\title{
Social marketing and higher education: partnering to achieve sustainable development goals
}

\author{
Chiara Hübscher
}

\author{
Department of Design, Production and Management, \\ University of Twente, Enschede, The Netherlands and \\ Hamburg School of Business Administration, Hamburg, Germany \\ Susanne Hensel-Börner \\ Hamburg School of Business Administration, Hamburg, Germany, and \\ Jörg Henseler \\ Department of Design, Production and Management, University of Twente, \\ Enschede, The Netherlands and Nova Information Management School \\ (NOVA-IMS), Universidade Nova de Lisboa, Lisbon, Portugal
}

\begin{abstract}
Purpose - Accomplishing the United Nations' Sustainable Development Goals (SDGs) is imperative for societies to meet their grand challenges. Achieving these goals by 2030 requires sustainability change agents with a can-do-attitude. This study aims to show how institutions of higher education can become partners for social marketing in bringing forward such change agents.

Design/methodology/approach - Taking a case study approach, this paper examines a master's programme to identify factors relevant to educating sustainability change agents that can serve as a basis for a social marketing planning primer to foster the SDGs.

Findings - This study presents the social marketing discipline with a viable option for supporting the achievement of the SDGs through higher education. Its contributions are twofold. First, it is shown that when interdisciplinarity and a project-based approach are conceptualized and organized to create a motivating and meaningful learning environment with the SDGs as guiding principles, students, as sustainability change agents, can increase awareness and have the potential to generate impacts regarding the SDGs at the individual, organizational and institutional levels. Second, based on this, the paper provides guidance to social marketers regarding the planning of a campaign targeting higher education institutions. The authors argue that the aim of this campaign should be to promote the implementation of the SDGs as guiding principles above all, as this can facilitate the process of students becoming sustainability change agents who help achieve the goals in a timely manner.

Research limitations/implications - Whilst single case studies are usually limited in drawing generalizations, the present study offers a starting point for investigating the role of universities as a target group for social marketing in fostering further sustainable development. Building on its findings, future

(C) Chiara Hübscher, Susanne Hensel-Börner and Jörg Henseler. Published by Emerald Publishing Limited. This article is published under the Creative Commons Attribution (CC BY 4.0) licence. Anyone may reproduce, distribute, translate and create derivative works of this article (for both commercial \& noncommercial purposes), subject to full attribution to the original publication and authors. The full terms of this licence may be seen at http://creativecommons.org/licences/by/4.0/legalcode

The authors would like to thank the guest editors and the three anonymous reviewers for the useful comments and constructive suggestions.

Funding: The author(s) declared that no grants were involved in supporting this work.
\end{abstract}

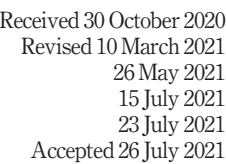

Accepted 26 July 2021 
research could test the proposed social marketing planning primer and evaluate the impact on the SDGs at a larger scale than only one university.

Practical implications - It is proposed to use the findings of the study to model a social marketing campaign aimed at universities to motivate them to help develop sustainability change agents in all disciplines by integrating the SDGs as guiding principles for study programmes.

Social implications - Students' impacts range from leading peers to buy sustainable products and consume less to influencing a company to adopt sustainable packaging, thereby contributing to social change.

Originality/value - This study is among the first to examine the possible effect of a study programme on the SDGs at different societal levels by taking the perspectives of multiple stakeholders into account and combining the theory of higher education with sustainability and social marketing.

Keywords Sustainable development goals, Change agents, SDGs, Responsible management education, Sustainable management education

Paper type Case study

"A good education changes what you know, a great education changes who you are". Prof. Richard K. Miller [1]

\section{Introduction}

On 25 September 2015, the United Nations General Assembly adopted the 2030 Agenda for Sustainable Development (UN, 2015). At the core of this framework are 17 sustainable development goals (SDGs). These goals address the global challenges of the twenty-first century and call all signatories to action to secure a sustainable and peaceful life on earth for all people. Consequently, accomplishing the SDGs requires joint commitment from governments, non-governmental organizations (NGOs), academic institutions and the private sector, as well as from individuals at the local, national and international levels (Frank and Cort, 2020, p. 18; Weybrecht, 2017, p. 84).

However, a global survey of 27,000 people across several levels in politics, business, science and research, the media and civil society revealed an average level of awareness of the SDGs of less than 50\% worldwide (Frank and Cort, 2020, pp. 4). This indicates that after five years, fewer than one in two persons in the world knows the goals, although only nine years remain for their accomplishment. Yet, awareness alone does not solve the problems that underlie the SDGs. As human behaviour, such as increasing $\mathrm{CO}_{2}$ emissions by riding a car or disposing of plastic waste in oceans, has led to many of these global problems, human behaviour is at least part of the solution. However, fundamental alterations in behaviour at the individual and societal levels are required. Answers are needed as to what can be done for the SDGs to flourish as a framework for concrete action towards more sustainable development (Frank and Cort, 2020, pp. 4, 18).

The good news is that as a discipline, social marketing can be part of or even become an important driver of, solutions based on integrating the SDGs into the mind and behaviour of individuals (Carvalho and Mazzon, 2015, p. 180; Truong, 2014, pp. 27). Prior research has shown social marketing's potential to induce behavioural change in a target audience, thereby increasing collective social welfare. This is especially true in areas such as health, the environment and the family (Kassirer et al., 2019, p. 209; Lee and Kotler, 2011, p. 7; Truong, 2014, p. 16; Van Esch, 2017, p. 16), all of which are, to some extent, present in the social issues covered by the SDGs. For example, Duffy et al. (2020, pp. 110) present a social marketing approach that can guide governments, organizations and individuals to increase parental leave uptake by fathers. They argue that by achieving such an increase, gender inequality can be reduced. Greater gender equality, in turn, is recognized by the UN as a target in SDG 5 (UN, 2015, p. 14). In addition to this example, however, research on social 
marketing initiatives that focus not only on the individual (downstream with an impact on the micro level) but also on the surrounding system (midstream with meso- and upstream with macro-level impact) is still limited, although it is needed to approach such complex and wicked problems of sustainable development (Duffy et al., 2020, p. 111). Underestimating the influence of cooperative action from key players (e.g. organizations and institutions) in a societal system of many stakeholders whose collective behavioural change is needed risks ignoring the potential of such collective action to meet the SDGs (Andreasen, 2002, p. 8; Duffy et al., 2020, p. 111).

Since the beginning of the century, there has been a growing belief that higher education should prepare students to become responsible managers and equip them with competencies allowing the creation of a sustainable future (Avelar et al., 2019, pp. 2; Haertle et al., 2017, p. 67; Molderez and Fonseca, 2018, p. 4397; Ramboarisata and Gendron, 2019, p. 1). If members of the next generation, made up of current students, become sustainability change agents who help create impacts beyond the micro level of behavioural change, they can contribute to accomplishing the SDGs by raising the awareness and showcasing how to act in a more sustainable manner. Hence, the higher education sector can be regarded as an important player in the societal system that social marketing could address to foster the collective action of students as change agents. This paper takes up and further develops this mission and calls social marketers to target higher education institutions, their students and related stakeholders as part of a midstream social marketing campaign.

The study presents the social marketing discipline with a viable option for supporting the achievement of the SDGs through higher education. Social marketing can help to embed the framework of the SDGs in society by encouraging universities to give their study programmes the SDGs as their overriding guiding principles to increase awareness of the goals in various disciplines and subject areas and to train students as change agents. This paper's contributions are thus, twofold. Firstly, the study's findings demonstrate that students who acquire competencies for sustainable development in a learning environment based on interdisciplinarity and a project-based approach can generate impacts regarding the awareness and achievement of the SDGs and thereby show that education can offer a greater potential than merely changing attitudes, namely, changing behaviour. Secondly, based on this, the paper proposes a planning primer for a social marketing campaign targeted at higher education institutions, the aim of which should be to promote above all the implementation of the SDGs as guiding principles in any study programme, as this can facilitate the process of students of any discipline becoming sustainability change agents who help achieve the goals in a timely manner.

The paper first outlines the interplay between social marketing and higher education for sustainability. The next section addresses the methodology used and introduces a master's programme as a case study. The "findings" section then presents examples of the impact of the master's programme on the achievement of the SDGs and evaluates the case with regard to education on sustainable development and social marketing planning.

\section{Theoretical background}

Social marketing, like commercial marketing, is a marketing discipline and as such makes use of theories and research to create campaigns with the intent of influencing the behaviour of a target audience (iSMA, 2017, p. 7; Lee and Kotler, 2011, p. 9; Lefebvre, 2012, p. 120). Therefore, behavioural change is the bottom line of social marketing, meaning that a social 
marketing campaign is deemed successful if behavioural change is achieved (Andreasen, 2002, p. 7; Lee and Kotler, 2011, p. 9).

Kotler and Zaltman introduced the concept of social marketing and provided the first definition, whilst other authors developed the concept further (Truong, 2014, p. 22; Table 1).

As presented in Table 1, all definitions of social marketing share a commitment to carefully designed and planned approaches to deliver a successful campaign for behavioural change. Involving the target audience to inform social marketing campaigns is what the latter definitions have in common (iSMA, 2013; French and Gordon, 2015, p. 20; Saunders et al., 2015, p. 165). This approach of the social marketer taking an active designer role is also evident in the definition of Saunders et al. (2015, p. 163), who claim the target audience must be enabled to participate in social change.

The International Social Marketing Association (iSMA) proposed one necessary marker and six elements that together form the core principles of successful social marketing campaigns: the facilitation of personal and social goods is the marker:

- Setting explicit goals.

- Citizen orientation and focus.

- Value proposition delivery.

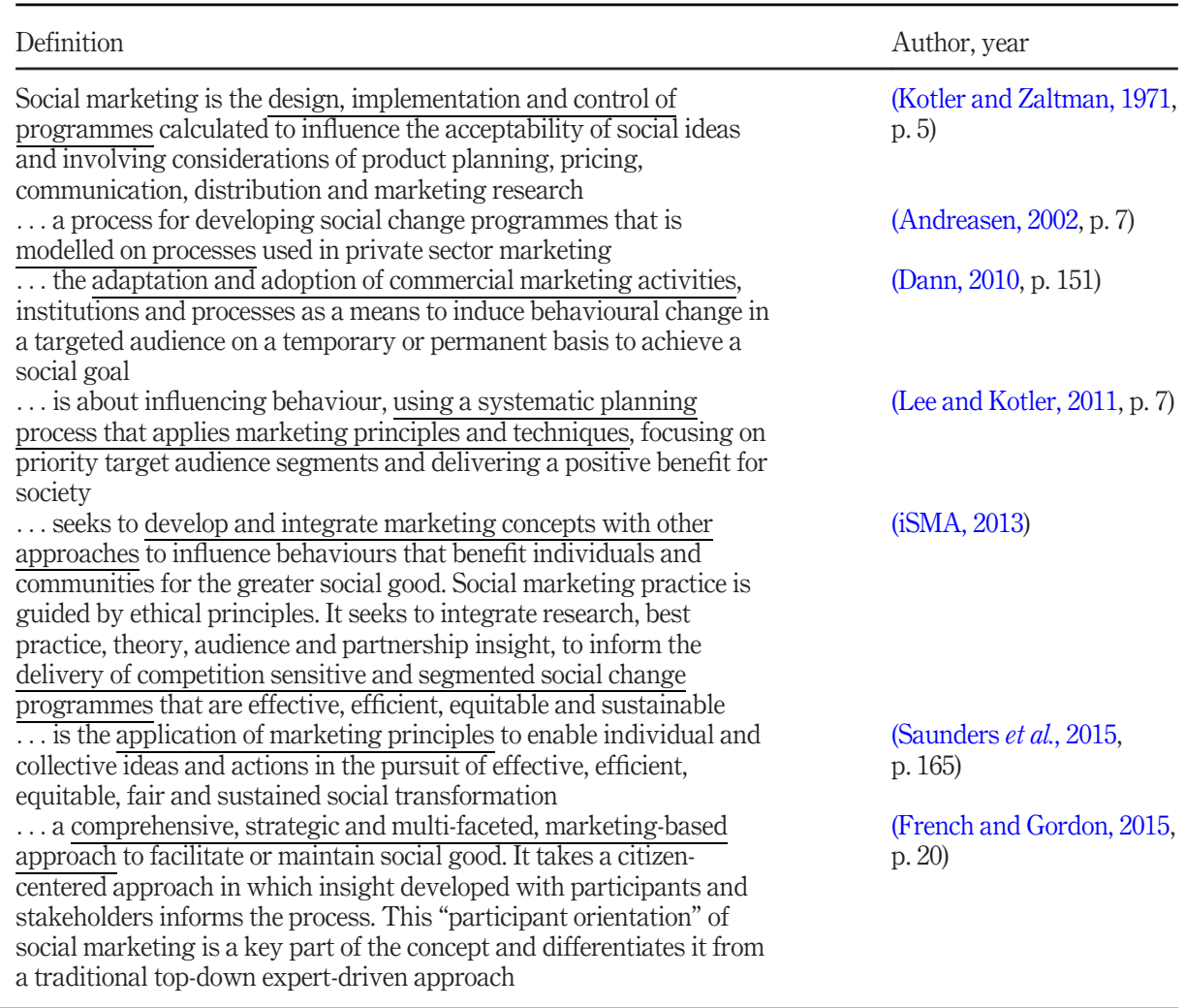

Table 1.

Social marketing definitions 
- Informed audience segmentation.

- Competition, barrier and asset analysis.

- Critical thinking, reflexivity and ethical behaviour are the necessary elements (iSMA, 2017, p. 4).

When all elements are present in a campaign with the corresponding marker, the iSMA considers the social marketing campaign to embody best practices (iSMA, 2017, p. 8). Several researchers, such as Andreasen (2002, p. 7), Lee and Kotler (2011, p. 18) and McKenzie-Mohr (2000, p. 546), explicitly highlight the need to understand the target audience and the drivers of their behaviour.

Behavioural change underlies psychological theories that help identify benefits and barriers to behavioural change and should also be considered when planning a social marketing campaign. Consequently, social marketing campaigns have proven to be more effective when they are created using behavioural change theory as a conceptual framework (Van Esch, 2017, p. 30). Among the most frequently reported theories is the theory of planned behaviour (TPB) (Truong, 2014, p. 24; Van Esch et al., 2013, p. 101), which serves as the underlying theory to explain behaviour in the present study. The basic assumption of the model is that a person's intentions to behave in a certain way ultimately lead to a certain behaviour. The intentions to behave are determined by a person's attitude, normative beliefs and perceived behavioural control. Normative beliefs refer to the perception of social pressures to perform or not to perform a certain behaviour. Such pressures usually stem from people, organizations and similar entities that surround the person. Perceived behavioural control refers to whether the person will find it easy or difficult to perform the behaviour (Parkinson et al., 2018, p. 842). If a person's behaviour is to be changed, behavioural intentions must also be changed (Van Esch, 2017, p. 30). Therefore, designing and planning a successful social marketing campaign requires the social marketer to understand a person's attitudes and perceived behavioural controls, as well as perceived social norms.

When a social marketing campaign is theoretically well-informed and successfully implemented, the impact can reach different levels. A more detailed explanation of these levels follows.

\section{Levels of social marketing impact}

The behaviour of any individual takes place within an ecological system where everything is interrelated and the behaviour of every individual affects the behaviour of others (Brennan et al., 2016, p. 223). Accordingly, research findings claim that social marketing campaigns become more effective, efficient, sustainable and equitable when their approach encompasses the whole system and does not only address the individual. The system can include actors such as organizations, communities and policymakers (French and RussellBennett, 2015, p. 143; Lefebvre, 2012, p. 120). In the social marketing literature, this shift in focus from the individual to the broader system is reflected in a discussion of how change is induced. Downstream social marketing refers to inducing behavioural change in the individual, whereas midstream and upstream social marketing target the system surrounding the individual. The corresponding levels of impact are micro, meso and macro (Lee and Kotler, 2011, p. 18; Truong and Dietrich, 2018, p. 59, Truong et al., 2019, p. 181). Whilst downstream social marketing targets the individual, and therefore, impacts the micro level, the meso-level impact of midstream social marketing involves friends and family, as well as the workplace and the macro-level impact of upstream social marketing involves politics and society at large (Lee and Kotler, 2011, p. 18). The described principles 
and theories underlying a social marketing campaign can be applied to influence target audiences at all levels (Andreasen, 2002, p. 8; Andreasen, 2006, p. 11). Targeting upstream and midstream audiences can be worthwhile, as actors on the meso and macro levels, in turn, influence the micro level downstream. Policymakers, corporations, schools and communities of any kind can become gatekeepers by facilitating behavioural change in individuals (Andreasen, 2006, p. 5; Duffy et al., 2020, p. 111; Lee and Kotler, 2011, pp. 10, 23). However, a systematic review by Truong (2014, p. 22) revealed that most social marketing studies have dealt with the downstream approach.

This study seeks to contribute to research that can inform the upstream but particularly the midstream approach of social marketing. Higher education is chosen as a potential partner in supporting the behavioural change of individuals towards increased sustainable development and contributions to the SDGs in particular. The next section looks at the theoretical foundations found in the literature with regard to sustainability in higher education.

\section{Sustainable development and the sustainable development goals in higher education}

Since the turn of the century, there has been a growing belief that higher education should prepare students to become responsible managers and equip them with the competencies necessary to help create a sustainable future (Avelar et al., 2019, p. 2; Haertle et al., 2017, p. 67; Molderez and Fonseca, 2018, p. 4397; Ramboarisata and Gendron, 2019, p. 1). To create a common framework for education, the UN launched the initiative of Principles for Responsible Management Education (PRME) in 2007 (Annan-Diab and Molinari, 2017, p. 2; Haertle et al., 2017, $p$ 67). In adopting the SDGs, they widened this initiative and since then, many signatory higher education institutions have started to implement strategies for fostering the SDGs and sustainable development in general (Haertle et al., 2017, p. 67; Storey et al., 2017, p. 102). A wide spectrum of ideas and impacts have been investigated and the first results of the implementation are promising: Killian et al. (2019, p. 3) found a positive impact that one specific service-learning module can have on increasing undergraduate students' knowledge of sustainability and more specifically, of the SDGs. Other authors have studied a teaching concept that helps students address one specific SDG target (Ortiz and Huber-Heim, 2017, p. 329) and a leadership course for future managers (Corriveau, 2020, p. 2). Furthermore, Kolb et al. (2017, pp. 82) analysed a PRME signatory school's business management study programme regarding its relation to sustainable management based on its curriculum, co-curricular activities and the university's outreach efforts. Specifically, they considered how the school addresses the SDGs in this regard. All these examples indicate contributions to making the SDGs better known and understood within higher education. In addition, these examples show that the implementation of the PRMEs and SDGs in management education varies in terms of content, teaching methods and integration into the curriculum (Moratis and Melissen, 2021, p. 2).

Nevertheless, achieving the SDGs is about more than merely becoming aware of the issues. The curriculum and related pedagogy need to be revised to support students in acquiring the necessary competencies that will help them translate their awareness into real action that contributes to sustainable development (Gentile, 2017, p. 124). Through their systematic literature review, Wiek et al. (2011, pp. 204) identified five key competencies that any study programme in sustainability should promote, namely, systems-thinking competence, anticipatory competence, normative competence, strategic competence and interpersonal competence. Each of these key competencies refers to a complex of knowledge, skills and attitudes that enable those who acquire such competencies to perform tasks and solve problems that are related to issues, challenges and opportunities for sustainability. 
Sustainable development requires systems-thinking competence, which is the ability to understand and analyse the complex system of society, economy and the environment. Similar to social marketing (Brennan et al., 2016, p. 223), higher education must acknowledge that sustainable development takes place on different levels, i.e. in politics, in organizations and in individuals and that there are causal effects between actors at different levels within an ecological system where a sustainable development approach is implemented. To identify intervention points, future managers of sustainability must understand the dynamics of such social-ecological systems (Wiek et al., 2011, p. 207). Imagining what the future related to sustainable development in these systems could look like is called anticipatory competence. Envisioning the future requires overall creativity (Molderez and Fonseca, 2018, p. 4399; Wiek et al., 2011, p. 207). At the same time, envisioning the future also requires normative competence, the ability to assess whether the current and future state of the system can be deemed sustainable or unsustainable. This also involves questions of ethics (Wiek et al., 2011, p. 208). Knowing how to design and implement strategies that will lead to the envisioned future identified with anticipatory and normative competence is referred to as strategic competence. For higher education, strategic competence implies that students are able to determine, which systemic interventions for sustainable development are viable, feasible, effective and efficient. Strategic competence requires an action orientation (Wiek et al., 2011, p. 210). Finally, interpersonal competence is needed for sustainability. This is the ability that connects all of the above competencies and seeks to motivate and facilitate collaboration for the collective sustainable development endeavour. Interpersonal competence involves interdisciplinary thinking and an understanding of different positions, as well as empathy. Interpersonal competence also involves communicating and negotiating (Wiek et al., 2011, p. 211).

In their study, Molderez and Fonseca (2018, p. 4408) find that real-world experiences and service-learning approaches have the potential to teach students the key competencies identified by Wiek et al. (2011, p. 204). As sustainability is neither covered by a single academic discipline nor has a fixed end state, a dynamic, holistic, interdisciplinary approach to higher education will best permit the acquisition of the above-mentioned competencies (Molderez and Fonseca, 2018, p. 4397).

To foster systems-thinking competencies, higher education should engage external stakeholders, such as organizations, in learning about sustainability. Collaborating with stakeholders whilst working on group projects gives students a sense of belonging to a larger system and helps them understand connectedness. Furthermore, group work can foster the skills that are particularly required for interpersonal competence, such as empathy and communication (Molderez and Fonseca, 2018, p. 4399; Wiek et al., 2011, p. 211). Groups, however, should be kept small (approximately 10 to 15 people), as education that is directed at behavioural change - as is the case for sustainable development - has proven to be more effective in environments that present opportunities for interaction (Geller, 1989, p. 21).

Hence, a study programme to equip students with the competencies needed to foster sustainable development should involve at least some practical, collaborative and interdisciplinary elements. When higher education institutions apply these elements in their study programmes, they can also become partners for social marketing to foster sustainable development and the SDGs not only at the individual level but also at the meso and macro levels. The next section outlines how the concepts of social marketing and higher education for sustainability can be brought together and how this can inform a midstream social marketing campaign to create behavioural change that contributes to the achievement of the SDGs. 
Merging the concepts: Sustainability change agents for social marketing

By facilitating the acquisition of competencies for sustainable development through academic programmes, universities act as central players in societal change and foster the achievement of the SDGs (Corriveau, 2020, p. 1; Haertle et al., 2017, p 67; Ndubuka and ReyMarmonier, 2019, p. 2; Stephens et al., 2008, p. 333; Truong and Dietrich, 2018, p. 59; Weybrecht, 2017, p. 85; Wood and Pansarella, 2019, p. 2). Students can be taught to become responsible managers who carry the idea of sustainable development to their friends and family, as well as to their workplace; hence, we call them sustainability change agents. To increase the effect, as many higher education institutions as possible are needed to engage in efforts to develop students of any discipline as change agents who promote the framework of the SDGs. For this purpose, a social marketing campaign targeting universities has the potential to promote awareness of the SDGs among universities and to call universities to support students in becoming sustainability change agents whose actions on micro, meso and macro level contribute to accomplishing the SGDs (Figure 1).

The next section introduces the case study approach to investigate the potential impact that universities can have on sustainable development initiatives in the sense of achieving the goals of the UN through their study programmes and students. It also helps to get an idea of the important elements of such a social marketing campaign targeting universities.

\section{Methodology}

The study examines how social marketing can play a role in establishing education for sustainable development at universities that foster teaching and learning initiatives related to the SDGs. When such "how can" questions are raised and a real-life phenomenon is studied, a case study approach is among the preferred research methods (Yin, 2009, p. 2). Aiming to expand the theory of what characterizes education for sustainability change agents using the SDGs, research benefits from the case study's rich contextual data and can provide outcomes that may be instrumental to students becoming sustainability change agents (Eisenhardt and Graebner, 2007, p. 25; Rynes and Gephart, 2004, p. 455). The case

Figure 1.

Concept map of the study of a social marketing campaign targeting universities

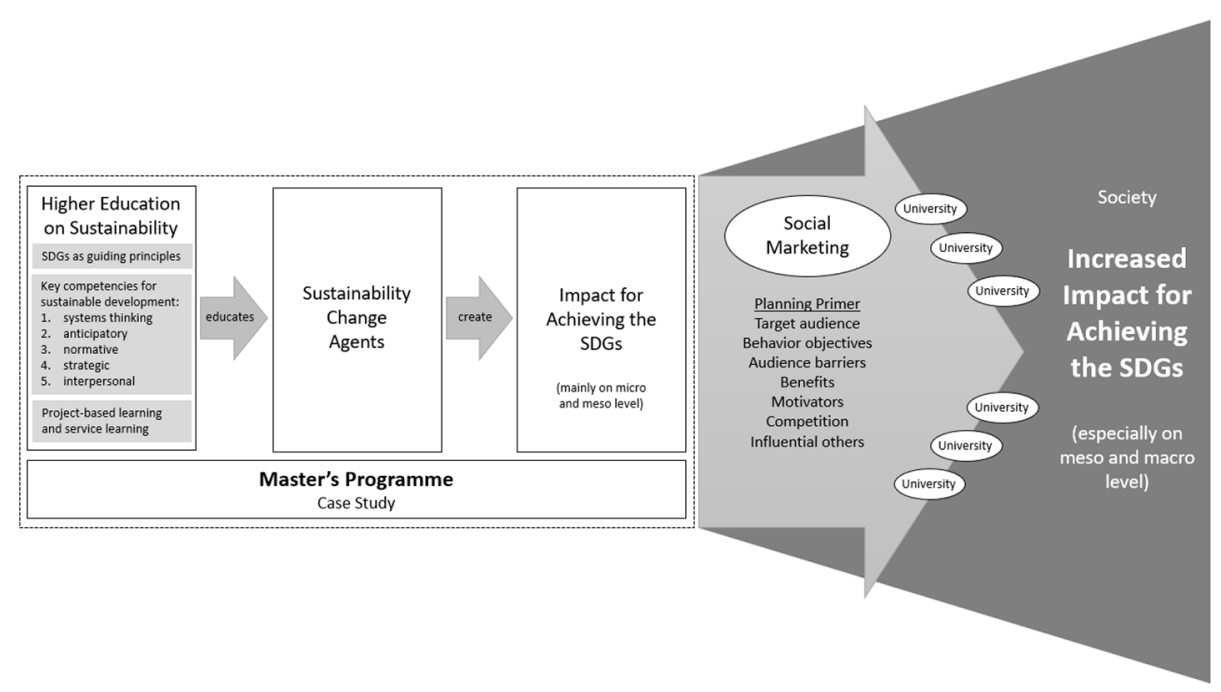


study method can compellingly illustrate a real-life phenomenon. This fits the aim of presenting the social marketing discipline with a guide for creating a campaign that targets higher education institutions, study programmes and students, as the case can serve as a real role model (Siggelkow, 2007, pp. 21).

The master's programme selected as the case for this study is a part-time programme that has been offered at a private business school in Germany since 2018. As a 30-monthlong programme, it leads to a state-recognized Master of Science degree accredited by the Foundation for International Business Administration Accreditation. The business school and the programme itself emphasize responsible management education [2]. The study programme under investigation is structured to allow a combination of study and work. The business school is an academic partner of more than 300 cooperating companies, which ensures that the case has both an academic and professional perspective. The programme's vision is to enable students to shape digital transformation and to foster sustainable development in these companies. The programme encourages very interactive learning through a project-based teaching approach and by allowing a maximum of 18 students per academic year. It also incorporates the sustainability challenge module, which applies service learning in the form of volunteer engagement with NGOs or social initiatives. Although it is anchored in the field of business studies, the programme straddles various disciplinary boundaries. It is, therefore, assumed that the programme incorporates all three elements that the literature has identified as important (Molderez and Fonseca, 2018, p. 4397), namely, it is practical, interdisciplinary and collaborative. As the goal of the envisioned social marketing campaign should be to promote the SDGs, it is also a decisive factor that the study programme makes continuous reference to the SDGs [3]. From a basic search on Google and masterstudies.com, we see that few programmes have such a focus on the SDGs. Table 2 presents examples of master's programmes that have the term "sustainability" in their title and refer to the SDGs.

Comparing the master's programmes with the selected programme, we also find it a good match because it is the only one that promises to refer to the SDGs in all its modules, in contrast to references to single SDGs or references made by single modules only. The SDGs serve as guiding principles for the different stakeholders involved in the programme and for the programme's content. The selection of the programme was also made for practical reasons. As two of the authors were involved in the development and conception, as well as the implementation of the study programme, we gained access to internal university data that could otherwise not be explored and that further supports the method's selection (Eisenhardt and Graebner, 2007, p. 25; Rynes and Gephart, 2004, p. 455). The strength of the case study approach is that it can advance the understanding of an applied field of study, thereby also improving its practice (Merriam, 2009, p. 43, 51). The study of the case has the potential to improve practice in that it can, to some extent, serve as efficacy testing for a sample target audience (Van Esch, 2017, p. 18). We present a single-case study, where the unit of analysis is the specific master's programme.

\section{Data collection}

The case analysis is based on several complementary sources of evidence, as proposed by Yin (2009, pp. 2, 101, 114). By measuring one phenomenon using multiple sources, we provide construct validity and meet the prerequisite for triangulating interview data with other material, thereby limiting bias (Goffin et al., 2019, p. 21). The different sources of evidence we use are specified in Table 3.

Keeping in mind the two objectives of this study, we argue that the stakeholder interviews, as well as the student testimonials, course evaluations, project reflections and 
JSOCM

\begin{tabular}{llll}
\hline Master's study programme & Country & Field of study & Reference to SDGs
\end{tabular}

\begin{tabular}{ll}
\hline Global business and & The Business-related \\
sustainability* & Netherlands
\end{tabular}

Referenced in one core module and two electives, e.g. in the module global business strategies: "global issues are portrayed as the sustainable development goals (SDGs). They will take a more

Sustainable production Sweden Manufacturing management* prominent role in this course" Three specific SDGs form a guideline for the overall programme[7]: "the programme is anchored in addressing the three dimensions of sustainability in the context of industrial production system development and change. As such, it focuses directly on fostering the achievement of sustainable development goals Sustainability* USA Interdisciplinary (SDG) 9, 12 and 13 ..."

Mentioned in the overall introduction to the course, not indicated for individual modules [8]: "the SDGs requires a strategic approach to applying global solutions at the local level ... The ... programme takes on the challenging intersections of such global and local challenges by equipping students to evaluate and (re-)produce resilient and sustainable responses"

Sustainable chemistry* Germany Natural sciences Referenced as Agenda 2030 in one module's title[9]: third semester "project work, chemistry, sustainability and the Agenda 2030 "

Digital transformation and Germany Business-related at the Guiding principle for the overall sustainability core with several links to programme - all modules refer to other disciplines at least one SDG[10]; e.g. the accreditation documentation (p. 11) says: "the 17 global goals for sustainable development of the United Nations (also called sustainable development goals/ SDGs) serve as a guiding principle for the entire study programme and all stakeholders involved This study objective is firmly anchored in $\S 1$ of the programmespecific regulations." In addition, the module descriptions outline, which SDGs are best addressed by the content of the module

Table 2.

Examples of master's programmes in sustainability that provide an explicit reference to the SDGs Note: *See masterstudies.com 


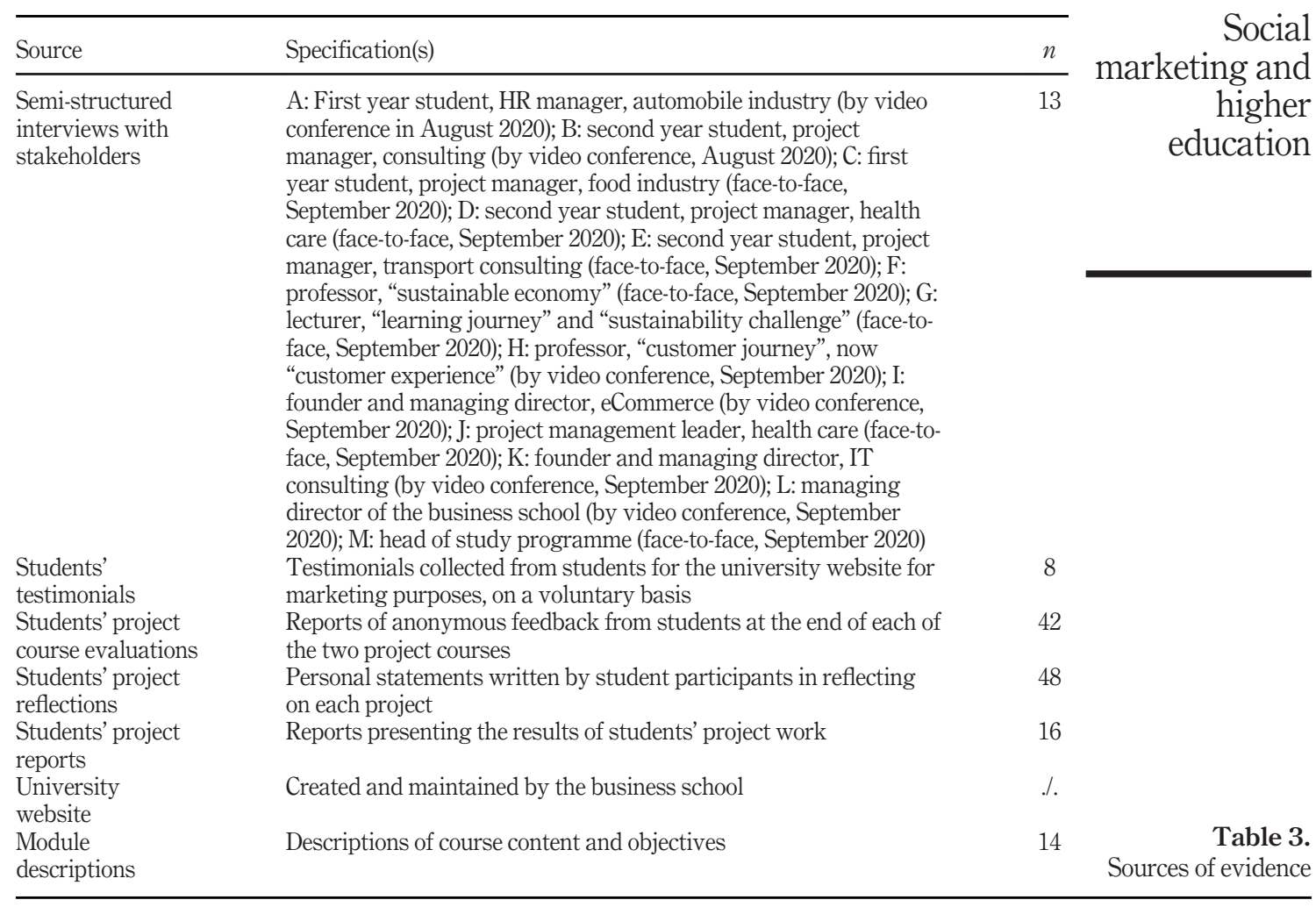

project reports, can provide us with insights regarding the impact of students on the different levels, as well as regarding specifications about the target group, behavioural objectives, audience barriers, benefits, motivators and influential others. The university's website and the module descriptions are used as supporting material to better understand what has been said or written about the programme. In all, we conducted 13 semi-structured interviews with an average duration of $42 \mathrm{~min}$, excluding the interviewer's introduction, which is in line with sample size requirements for qualitative research (Creswell, 2007, p. 61, Van Esch and Van Esch, 2013, p. 228). Moreover, we argue that we achieved saturation in terms of the different perspectives on the study programme, as we covered the different stakeholder groups that are involved and of interest in informing a social marketing campaign, including students, lecturers, university management and students' employers. The latter are especially important with regard to the potential midstream- and upstreamlevel impacts of the programme. We selected employers who hired at least one student from the first cohort so that the employers were able to observe and make a statement about students and their potential impact over a longer period. The selected employers represented an eCommerce, a health care and an information technology (IT) consulting company ranging from less than 50 (small and mid-size enterprises) to more than 2,500 employees, respectively. Including the perspectives of such diverse participants, again, mitigates bias in data collection (Eisenhardt and Graebner, 2007, p. 28). We audio-recorded the interviews with the interviewees' consent and had them fully transcribed to facilitate the analysis. As 
we conducted the interviews in the interviewees' native language, we first established the coding system for the content analysis in German and then translated it into English. The process of content and further analysis is described in the next section.

\section{Data analysis}

To systemically build categories that describe the aspects that are important for informing social marketing, a qualitative content analysis of the interviews and corresponding material was carried out (Schreier, 2012, p. 12), as this has been described as an appropriate way to build a theory based on cases (Kohlbacher, 2006). Such an analysis is systematic in that it follows predefined rules to build categories (Mayring, 2010, p. 59). The structural variant of qualitative content analysis was selected to develop the categories deductively and inductively, allowing for the emergence of important aspects to form new categories whilst analysing the material (Mayring, 2010, pp. 65, 83; Schreier, 2012, pp. 25, 35; 44). The deductive categories were adopted from the literature on higher education, according to which we were specifically looking for evidence that the programme fosters key competencies for sustainable development; that these enabled students to act as sustainability change agents; and that, as sustainability change agents, they were able to create an impact on the micro, meso or macro level. The categories were finally grouped under four main themes:

(1) Person-specific factors that describe the sustainability change agent, which represent a student's can-do-attitude, as well as their expertise and knowledge regarding sustainable development.

(2) Study programme-defining factors related to the content, including the SGDs as guiding principle and interdisciplinarity.

(3) Study programme-defining factors related to format, organization and structure, described as the duality and project-based approach of the programme, as well as the philosophy and culture of learning.

(4) Results in the form of either impact with regard to the SDGs or barriers preventing impact (Table 4).

We used MAXQDA software to facilitate the coding process (Mayring, 2010, p. 113). One of the coders coded some parts of the interviews twice to test and adjust the coding system before actually starting the analysis. All three authors reviewed the coding system to ensure that they shared a common understanding regarding the language used for units of analysis.

We provide validity in the form of data triangulation by applying several heterogeneous sources of evidence and comparing their results. We further support validity through quotes by the research participants that provide the reader with a better understanding of how we arrived at the conclusions (Mayring, 2010, pp. 50, 116; Schreier, 2012, pp. 45). We analogously translated quotes from German to English. To arrive at the conclusions, we kept in mind theories from the educational and social marketing fields. Hence, we also provide theoretical triangulation, which adds to the validity of this study (Van Esch and Van Esch, 2013, pp. 233).

We interpreted the findings of the qualitative content analysis with two criteria in mind, namely, firstly, the frequency with which a code appeared in the material was taken as underpinning the code's significance (Mayring, 2010, p. 51; Kuckartz, 2019). Secondly, we assumed a code to be more significant when it appeared in material derived from several 


Category
Theme 1: Person-specific factors: Students as change agents
Can-do-attitude

Can-do-attitude

Expertise and knowledge

Theme 2: Study programme-specific factors: Content

SDGs as guiding principles

Interdisciplinarity

Theme 3: Study programme-specific factors: Format, organization and structure Duality and project-based learning approach

Philosophy and culture of learning

Theme 4: Results

Impact

Barriers and critical remarks
Category explanation

Positive attitude towards change, creative will, motivation, courage and belief regarding sustainable development Student's expertise regarding sustainability or student's knowledge about sustainability

Framework for navigation to business schools regarding curricula and contents that serve sustainable development Cross-thematic content from various disciplines and changes in perspectives

Integration of external stakeholders, e.g. companies, servicelearning and the application of theory in practice

Study programme as a trial arena for behaviour in support of sustainable development, characterized by small group sizes, lecturers as role models and the openness for discussion

Positive effects regarding (behavioural) change towards sustainability Factors hindering positive effects regarding (behavioural) change towards sustainability
Social marketing and higher education

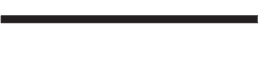


regarding the awareness and the achievement of the SDGs and to determine how this can guide social marketers regarding the planning of a social marketing campaign to foster the SDGs. To achieve the second objective, the question of how study programmes train students as sustainability change agents is raised. The findings section is, therefore, broken down into three subsections. Firstly, evidence for the students' impact is provided. Secondly, questions of how studying enabled them to have this impact are answered. Thirdly, the implications for planning a social marketing campaign targeted at higher education are analysed.

\section{Overall impact of students on reaching the sustainable development goals}

According to Van Esch (2017, p. 18), direct, short-term effects, such as changes in awareness and knowledge, translate into the impact of a social marketing campaign, whereas long-term effects at the societal level are called the outcomes of the campaign. Although the results of this study go beyond mere changes in awareness and knowledge, students created an impact rather than an outcome. As the study is not longitudinal, potential outcomes can only be estimated.

The analyses and results demonstrate that the business school's programme has an impact on the individual, organizational and institutional levels, which correspond to the micro, meso and macro levels. Examples of each level were coded with labels summarized as the impact category during data analysis and are presented next.

On the individual level, the students themselves changed their own behaviour first after enrolling in a study programme related to the SDGs, which is in line with the participatory views of change put forward by Sen (1999, p. 4, 11), Kotter (2018, p. 9) and Saunders et al. (2015, p. 163). For example, one of the student's reports adopting new waste separation patterns, whilst another reveals having become vegetarian for reasons of sustainability. This represents a small contribution to various SDGs, e.g. SDG 3 - "good health and wellbeing", SDG 12 - "responsible consumption" and SDG 13 - "climate action" through reduced emissions that are associated with the consumption of meat. In addition, the student changed her way of life in many ways to the extent that she believes herself to be a different person:

Student: "If my friends look at how I lived two years ago and if they look at me today, then many of those I last saw a year and a half ago hardly recognize me and are like, 'Is this you?' 'Yes, this is me now'."

There are several examples of relatively short-term transactions in which students make a sustainable contribution, e.g. by supporting a social project in the region for one semester as part of the service-learning module; however, other transactions include a long-term perspective for the students, e.g. when they decide to continue volunteering beyond the scope of the service-learning module or when they get to select their employer. The latter may have an impact on SDG 8 - "decent work and economic growth" by attracting skilled labour, i.e. future graduates, to work for companies that care about their material footprint, equal employment opportunities and social protection. Overall, the study programme contributes to a can-do-attitude and helps students act as role models, as the following quote illustrates:

Student: "I think the programme makes one a better person, someone who contributes more to society, who looks to the left and right, takes other perspectives into account to actually see where one can change something, [...] where one can improve something. [...] I have the feeling that it just takes me a lot further on a human level." 
At the organizational level, the impacts students achieved at the companies where they were employed range from incorporating sustainability in general to providing a stage for the SDGs in products, projects and campaigns. Even in companies where the topic of sustainability was not on the agenda previously, students were able to generate an impact by creating a sustainable environment for themselves in the workplace, even if their tasks were not necessarily related to sustainable development. This indirect impact is initially important because the business sector has a key role to play in achieving the SDGs because of the potential influence of businesses on customers, employees, suppliers and the like (Weybrecht, 2017, p. 84):

Employer: "The fact that [the topic of sustainability] is on the agenda at all and not at the bottom [despite the question of costs, for example], is certainly because of these [students]. [...] thanks to this programme, those SDGs are actually slowly finding their way into the company and projects are now assigned to consider SDGs to achieve even better visibility."

In one of the first-year project modules, two students working in eCommerce performed research on sustainable packaging for the products that their company sells. They presented their results to the managing directors of their cooperating company and now their recommended course of action is being implemented in practice. This could contribute to SDG 8 - "decent work and economic growth", SDG 9 - "industry, innovation and infrastructure", as well as SDG 12 - "responsible production", as the implementation of the project can lead to increased resource efficiency and improved material footprint, etc.:

Employer: "We received many prompts from the two students in the field [of sustainability], not least through the RePack project on recyclable packaging, which was extremely interesting. [...] This project work [. . . ] is certainly a milestone."

As part of the same project module, other students examined the environmental footprint of websites and derived recommendations for action to reduce $\mathrm{CO}_{2}$ emissions for highperformance websites, which, in turn, were made available to organizations and the broader public through a publication in the Handbook of Climate Change Management (Geringer et al., 2020, p. 1).

The students' outreach regarding fostering sustainable development was reported to be felt especially strongly in the students' personal environment, namely, among friends and family. The following quotes underline this type of impact at the meso level:

Student: "Because I study sustainability, it is natural that I will have discussions on a different level. [...] I have an older brother [...]. He has stopped smoking - not because of his health, but because of sustainability [...] and he also eats much less meat [...]. It is the same with my parents, my closest friends, but it is also true for my wider circle of friends. [...] Then the mobile phone collection campaign took place [as part of the course] and that was the very first time I had to talk to complete strangers about why sustainability is important."

Another student: "My roommate applied to a bank [...] also because its deposits support renewable energies rather than resource-consuming energy generation. [.. .] He said, 'I actually want to work somewhere where I can work with a clear conscience."

Moreover, there is evidence of an impact on the students' surrounding environment at the university itself and to some extent, on the environment in which the lecturers act outside of their role in the master's programme. Other study programmes that adopt a commitment to the SDGs and even the university as a whole, illustrate such an extended environmental impact, again at the meso level, most likely contributing to SDG 4 - "quality education" and SDG 17 - "partnerships for the goals" by introducing education for sustainable development 
in curricula and teaching, leading to the exchange of knowledge and expertise regarding sustainable development:

Lecturer: "At this workshop on our [university] mission statement, a colleague said, 'Why don't we align our mission to the SDGs?" [...] You can see that impulses from the study programme are passed on to the mothership, the university. It is great that ideas from there are also fed into other courses - whether it be didactic or in terms of content."

Table 5 summarizes selected findings with respect to the different levels and provides an outlook on the possible impact on the macro level.

These examples show that students have the potential to become sustainability change agents when their study programme provides them with the necessary competencies and tools to spread the idea of sustainable development and the SDGs beyond the university. A closer look is taken at the competencies in the next section before the process of what led the students to create impacts and what this means for social marketing are presented.

Case evaluation in terms of the impact of higher education on sustainability

Engaging in a change process often requires people to move beyond their comfort zones (Cameron and Green, 2015, pp. 211). An environment that provides a trial arena in that it lets students test new attitudes and behaviour for sustainable development among like-minded people first can be key to slowly approach the edge of their comfort zones and moving beyond. According to the evidence, stakeholders find that the master's programme

\begin{tabular}{|c|c|c|c|}
\hline Impact & $\begin{array}{c}\text { "I" } \\
\text { Downstream/micro-level } \\
\text { (individual) }\end{array}$ & $\begin{array}{c}\text { "We" } \\
\text { Midstream/meso-level } \\
\text { (organizations, family and } \\
\text { friends) }\end{array}$ & $\begin{array}{l}\text { "All of us" } \\
\text { Upstream/macro-level (politics } \\
\text { and greater society) }\end{array}$ \\
\hline $\begin{array}{l}\text { Short- } \\
\text { term } \\
\text { examples }\end{array}$ & $\begin{array}{l}\text { - Students enroll in study } \\
\text { programmes that refer } \\
\text { to SDGs } \\
\text { - Students start } \\
\text { volunteering as part of } \\
\text { the service-learning } \\
\text { module (sustainability } \\
\text { challenge) }\end{array}$ & $\begin{array}{l}\text { - Company projects are } \\
\text { assigned to specific SDGs } \\
\text { - } \quad \text { Students publish a guide } \\
\text { to reducing } \mathrm{CO}_{2} \\
\text { emissions for high- } \\
\text { performance websites of } \\
\text { companies }\end{array}$ & $\begin{array}{l}\text { - Students collect old mobile } \\
\text { phones, thereby informing } \\
\text { the public about why } \\
\text { sustainability is important } \\
\text { - Educational policy } \\
\text { recommends integrating } \\
\text { the SDGs as guiding } \\
\text { principles in study } \\
\text { programmes (outlook) }\end{array}$ \\
\hline $\begin{array}{l}\text { Long- } \\
\text { term } \\
\text { examples }\end{array}$ & $\begin{array}{l}\text { - Student becomes } \\
\text { vegetarian } \\
\text { - } \quad \text { Student adopts new } \\
\text { waste separation } \\
\text { pattern } \\
\text { - Student continues } \\
\text { volunteering beyond the } \\
\text { scope of the service- } \\
\text { learning module }\end{array}$ & $\begin{array}{l}\text { - Student's roommate } \\
\text { switches job to work for } \\
\text { company supporting } \\
\text { renewable energies } \\
\text { - } \quad \text { Student's brother } \\
\text { stopped smoking } \\
\text { - Company integrates } \\
\text { sustainable packaging }\end{array}$ & $\begin{array}{l}\text { - All study programmes } \\
\text { refer to the SDGs future } \\
\text { (outlook) }\end{array}$ \\
\hline
\end{tabular}

\section{Table 5.}

Examples of longand short-term impact regarding sustainable development and the SDGs at the micro, meso and macro levels
Student's roommate switches job to work for company supporting renewable energies

Student's brother Combanv inteorate

Company integrates sustainable packaging

\section{Upstream/macro-level (politics}

Students collect old mobile phones, thereby informing the public about why sustainability is important

Educational policy the SDGs as guiding principles in study programmes (outlook)

All study programmes refer to the SDGs future (outlook) 
demonstrates such a trial arena. This view corresponds with the codes in the category philosophy and culture of learning. Among other factors, the programme is characterized by small group sizes that allow students and lecturers to build a relationship of trust and easy exchange. The business school accepts a maximum of 18 students per academic year [4]. The small study group enables very close supervision of the students' individual learning and development:

Student: "We are quite close and can truly talk about every possible topic and there is always the feeling 'I can say what I want and I am not judged here'."

The data support the view of Geller (1989, p. 21), who advocates for education on behavioural change to take place in small groups to be most effective. Therefore, this characteristic is added to the list of necessary elements for designing a study programme that intends to foster sustainable development, although a maximum number of students for the small group cannot be established with certainty. However, a small study group alone did not achieve the desired effect. Rather, the small study group allows for interaction with others, e.g. other students and lecturers, by providing an openness to discussion. This contributes to the development of interpersonal competence in particular. Hernández-López et al.'s (2020, p. 9) study find that students acquire competencies related to business ethics, which is deemed part of normative competence, more effectively when they perceive their teachers as having ethical leadership qualities. It sets a good example for students if lecturers themselves engage in sustainable behaviour, as it increases credibility (Kanashiro et al., 2020, p. 8). From the interviews, there is evidence that lecturers indeed become role models for students and can have a positive impact on shaping students' attitudes regarding sustainability:

Student: "From my point of view, we have lecturers who are particularly committed. In addition, for this reason, they also encourage us to get involved and to commit to something that could also be outside of the study programme's context [...] the one lecturer I have in mind, she mobilizes and inspires and motivates us. I would definitely say she is a role model for all of us."

The lecturer's role is to be not only a role model but also a facilitator who supports "the students" transition from a passive attitude into being the protagonist of their own learning' (de Paula Arruda Filho and Przybylowicz Beuter, 2020, p. 8). Through the lecturers' invitation, students can engage in discussions and give feedback. Such discussions, in turn, can provide a platform for students and for lecturers to develop a community in which everyone engages in mutual learning. All participants of the study, except the employers, mentioned this in their interviews and it is also reflected in other sources of evidence:

Student testimonial: "I do not think many programmes have the sense of community among students and professors as strongly as it is with us".

Interaction with others that goes beyond the study group is very practically incorporated into the study programme through a project-based learning approach and service learning. In addition, it comes naturally from the duality of the programme. The master's programme is taught part-time, encouraging students to work whilst they are studying. In doing so, students can test the application of theories and models in real-life contexts and learn to assess their own actions. This kind of reality check seems to support developing a can-doattitude in students:

Employer: "I learned how valuable it is to make close contacts with people in business during my studies. Not only because you could get a great job afterwards, but because students [.. .] then learn very quickly whether what they were taught is relevant or not". 
Project-based learning, the major didactic approach of the master's programme, allows students to perform a reality check regarding the theories and models they acquired in the classroom. Four modules designate projects in their names, whilst most of the remaining modules work towards fostering project management skills in students [5]:

Student: "In 'Data-based Decision-Making', we actually had a mini-project where we did data evaluation -I find it amazing how realistic that was."

Not only engagement with companies gives students the chance to improve their interpersonal competence, but it can also contribute to strategic competence and systemsthinking competence. In the case of systems-thinking competence, Molderez and Fonseca (2018, p. 4399) argue that the integration of external stakeholders, i.e. companies, correlates with the students' feelings of connectedness and an understanding of the bigger picture regarding the system in which they are embedded. In line with their findings, this study's data also support the integration of a service-learning module in which students can do something for society as part of their studies. In the examined programme, the servicelearning module is designated as a sustainability challenge:

Student: "The Sustainability Challenge - perhaps that is the most formative. I was looking for something where I can get to know people from different countries, to get this global view [...]. In addition, we have discussed so many sustainability initiatives with each other in the course that we have already become much more aware of how the world works".

Wiek et al. (2011, p. 210) attribute an action orientation to strategic competence. They state that "this competence is about being able to "get things done" [which] involves familiarity with real world situations" (Wiek et al., 2011, p. 210) and this is what the students can benefit from when working in a company whilst studying. Almost $30 \%$ of the coded segments summarized as person-defining factors relate to students' positive attitudes towards change, their creative will, motivation and courage to take part in or lead a change process and their belief that they can do it. These characteristics resulted in the can-do-attitude category. A person's can-do-attitude seems to be an especially important feature considering that change agents often have to overcome barriers in the process of bringing others to change, such as having to assert themselves against older and more senior members of a company or society. Cameron and Green (2015, p. 9) support the idea of motivated individuals being change enablers. One key to establishing a can-do-attitude is expertise and knowledge. Being a credible change agent requires students to acquire knowledge and expertise regarding sustainability so that they have an idea of where the change process will lead and are competent in applying methods that will ensure success (Annan-Diab and Molinari, 2017, p. 4). Expertise enables students to present and defend their arguments in favour of the desired change. The ability to identify obstacles to change and knowledge of how to address them are among the most common learning objectives that Kelly (2013, p. 294) identified in the syllabi of existing social marketing-related courses:

Lecturer: "[. . .] so that you may have [. . .] an idea of which levers you might have to push or pull, where first and where it may be slightly more difficult. I think that makes things more productive and hopefully less frustrating".

In summary, expertise is connected to strategic competence through furthering a can-doattitude and to anticipatory competence by enabling students to envision a realistic picture of the future. The study finds that expertise is fostered by the interdisciplinarity of the programme's content and the SDGs as guiding principles. In the literature, several authors emphasize the interdisciplinarity of sustainable development and the need to take an interdisciplinary approach in educational programmes, as making sustainable development 
a reality involves many different disciplines (Annan-Diab and Molinari, 2017, p. 5; Ramboarisata and Gendron, 2019, p. 10; Wood and Pansarella, 2019, pp. 2). The challenges of the twenty-first century are complex and multifaceted. These can be translated into curricula through cross-thematic content from different disciplines and changes in perspective. Accordingly, change agents can benefit from being able to develop networks across different topics and between experts in different disciplines, which again supports the view of interpersonal competence proposed by Wiek et al. (2011, p. 211). Thus far, all interviewed stakeholders, especially students and lecturers, have attested to the underlying interdisciplinary approach of the programme as a success factor.

Extract from student reflections: "Even if I found the mixture of different disciplines and literary styles challenging, I see it as a personal gain to have experienced and lived interdisciplinarity in my studies not only across different modules, but within a research project".

The programme's website [6] and the module descriptions promise continuous reference to the SDGs and an alignment of the course content to the goals. Integrating the SDGs into the programme helps to embed them in the minds of the students and in the institution itself. The SDGs, therefore, provide a common sustainability language (Weybrecht, 2017, p. 85), offering a framework for navigation to business schools, especially regarding which content will be relevant to teaching sustainable development (Frank and Cort, 2020, pp. 4, Storey et al., 2017, p. 101). The business school's objective should then be to translate this framework into curricula that will, for example, familiarize its stakeholders with the goals (Weybrecht, 2017, p. 85). Cameron and Green (2015, pp. 25) add that goals in general help to achieve change, stating that the likelihood of achievement is dependent on how concrete the goals are.

Two students: "I actually think that [the SDGs] have given the topic of sustainability a more specific focus [.. .]" and "[.. .] the fact that the UN adopted these goals adds a certain level of seriousness".

Head of the business school: "I think that [the SDGs] are very important in terms of achieving a common commitment or, first of all, a chance to do so, by at least naming subject areas that need to be worked on [.. .] it is about creating identification".

Figure 2 summarizes the key findings regarding competencies and the concept of the programme, including teaching and learning approaches that support students in becoming sustainability change agents to foster the SDGs.

To answer the second research question, an evaluation of the case in terms of planning a social marketing campaign follows, considering the findings on the impact of higher education.

Case evaluation in terms of the implications for planning a social marketing campaign

To identify important aspects of planning a social marketing campaign targeting universities on the meso level and their students on the micro level, the case is analysed using the TPB. This means that the identified person-specific and programme-specific factors are investigated regarding their potential to influence attitudes, normative beliefs and perceived behavioural control, which determine behaviour according to the TPB. The planning primer presented at the end of this section outlines audience barriers, benefits, motivators, competition and influential others, all of which are likely to shape the attitudes, normative beliefs and perceived behavioural control of the target groups. As the resulting impact is primarily created by the students, we first look at this target audience before we turn to the universities. 


\section{JSOCM}

\section{Figure 2.}

Summary of study programme- and person-specific factors relevant to educating change agents for sustainable development

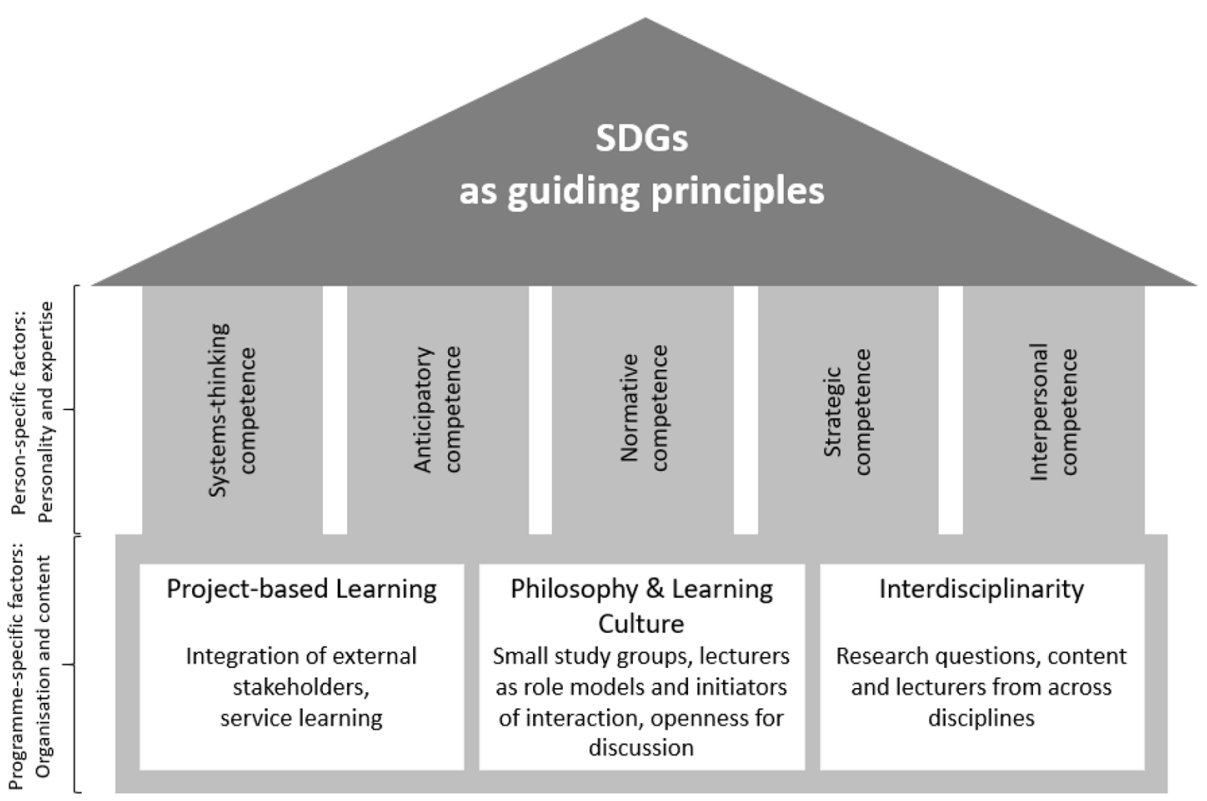

Regarding the students, as expected, the study finds that attitudes were generally positive towards change and sustainability even before attending the programme. Building on this, the study programme has the potential to increase perceived behavioural control by fostering expertise and knowledge. Expertise and knowledge in the field of sustainability ease the adoption of behaviour, which is in line with Prestin and Pearce (2010, p. 2021), who found that a campaign promoting sustainable behaviour, such as recycling, required efforts to first establish knowledge about this behaviour, such as which products are recyclable and which are not. Hence, a social marketing campaign that fosters knowledge and expertise regarding sustainable development and the SDGs on the micro level, in turn, can contribute to students changing their behaviour in favour of sustainable development and the SDGs, as well as to their ability to become a change agent. The SDGs, as guiding principles, play a role here as motivators because they offer a common language of sustainability. However, whilst they provide a guide as to the scope of sustainable development, some students perceive the goals' framework as a barrier because it does not quantify their contribution. Social marketing should address this issue in its campaign, e.g. by providing examples of what has been practically achieved by students to contribute to the SDGs and showing how these contributions are worthwhile.

Project-based learning and service learning can serve as a trial arena for new behaviour, i.e. a more sustainable way of behaving and should thus, be encouraged by social marketing campaigns. In these trial arenas, normative beliefs in the form of perceived social norms most probably work in favour of the new behaviour, as students can perform the desired behaviour among people who are usually like-minded or at least have the same interests regarding sustainable development based on their commitment to the study programme. Project-based learning and service learning are, therefore, considered audience motivators on the micro level: 
Student: "[...] that you are surrounded by people who are sensitized to [the topic of sustainability] and I think that sensitized me: That you have a lot to do with people who talk about it, [...] who behave also already more sustainably under certain circumstances, so that you can learn from them".

In contrast to what happens inside the classroom, social norms outside the classroom, e.g. at the student's workplace, can either work in favour of or against the adoption of sustainable behaviour and the role of students as change agents. For instance, when sustainability is on a company's agenda, employees most likely feel that acting sustainably is encouraged. In contrast, a rather neutral or even negative attitude of companies towards sustainability means that the normative beliefs speak against adopting sustainable behaviour and could present a barrier to students developing their full potential as change agents:

Student: "I have to say, especially in regard to higher hierarchical levels, I am actually still slightly frustrated and do not know how much I want to put up with it. I think sustainability is still [...] more of an issue that the company wants to communicate to the outside because it is in demand; more like a marketing label".

Nevertheless, social marketing should have as an objective promoting the engagement of external stakeholders, such as organizations, in study programmes. External stakeholders in general have a positive effect on students' acquisition of key competencies for sustainable development and should thus, be treated as influential others for the student target audience.

Turning now to universities as a target audience on meso level, it is acknowledged that whilst small group sizes can be a potential motivator for the student target group because they generally offer a secure environment for them to test new behaviour, for the university target audience, small groups can also present barriers because of the related costs:

Member of the university's management board: "[. . .] how does this pay off for me as a university? Because this degree programme - as nice as it is - does not scale like normal study programmes".

A social marketing campaign should address this issue by highlighting the benefits that are associated with small study groups, such as how it can set the university apart from the competition by allowing more classroom interaction and closer supervision of students by lecturers. Whilst interdisciplinarity can be another differentiating factor, it also opens the door for those who are suspicious of studying sustainability. In the present case, the interdisciplinary content of the study programme is signalled in the title, combining sustainability with digital transformation. For those who are attracted by the latter, the focus on interdisciplinarity can also enable access to the topic of sustainability:

Employer: "[...] that was actually my door opener on the topic of sustainability overall; then I asked myself [...] how can one combine the two topics?"

For the sustainability content of a study programme, the SDGs, with their many facets and dimensions, present universities and students with a guideline. The social marketing campaign should communicate this as a motivating factor on the meso level, as it has the potential to increase perceived behavioural control.

A further barrier for the university target audience stems from organizational structures and policies that universities adhere to, such as exam regulations. These do not always act in favour of interactive and innovative teaching approaches such as project-based or service learning and should hence, be addressed by a social marketing campaign in considering normative beliefs about how such regulations could be adapted to allow for more interactive and innovative learning: 
Lecturer: "[There was an] announcement from the examination office that now only individual grades can be awarded, which is extremely annoying to me, because of course this totally counteracts group work".

Structures and policies at universities are usually influenced by accreditation institutions, which should be taken into account by social marketing campaigns as influential others. Lecturers are also part of the influential others. Some lecturers, due to normative beliefs and perceived behavioural control, might stick to "the old way" of teaching instead of adopting new pedagogies and encouraging a dynamic learning culture. This is, however, what the social marketing campaign's success can benefit from: lecturers enabling students to acquire the competencies to act as change agents:

Lecturer: "IIt takes teachers] who themselves bring that enthusiasm [...]. Think about what the things in your life have been, that have carried you away the most. That was when people were authentic, involved, excited. Not just when they lectured from the textbook".

Table 6 summarizes the results in terms of planning a social marketing campaign and groups the individual factors regarding their meaning for the campaign elements on micro and meso level, e.g. whether they serve as a motivator or whether they represent a barrier.

\section{Discussion and conclusion}

It is less than 10 years left if the UN's 17 SDGs are to be achieved by 2030. Education can be of central importance here. Universities should become aware of their responsibility in their position as potential facilitators for sustainable development by training change agents. Thus, it is necessary for universities to create a learning environment that shapes students to become change-makers in terms of sustainable development. When social marketing identifies universities and their students as a priority target audience of a campaign, it has the potential to scale the effect that study programmes - as the one in the present case - can have on increasing awareness of the SDGs and educating students of various disciplines as sustainability change agents. The more universities are encouraged by such social marketing campaigns, the better known the SDGs become and the more change agents can help foster them. To achieve this, social marketing can benefit from using insights from higher education on sustainability as a benchmark. We present the case of a master's programme with reference to the SDGs as overall guiding principles and offer two contributions. Firstly, this paper provides an answer to the question of whether and how higher education students can be trained as change agents to generate an impact regarding the awareness and achievement of the SDGs and in doing so also demonstrates that education offers the potential to induce behavioural change. Secondly, it informs the planning primer of a social marketing campaign targeting universities and their students to foster greater interest in sustainable development and encourage behavioural change in favour of the SDGs. It, thus, contributes to the theory of higher education on sustainability, as well as social marketing planning and carries implications for education and more specifically for social marketing practice.

\section{Theoretical contribution}

The present study provides empirical evidence regarding the theory that informs higher education on sustainability. In regard to education on sustainable development, it builds on the framework of key competencies that was proposed by Wiek et al. (2011, p. 204) and extends this framework by adding elements of teaching and learning approaches for their acquisition, as well as using the SDGs as guiding principles to recommend a guideline for the education of sustainability change agents. The factors identified in the master's 


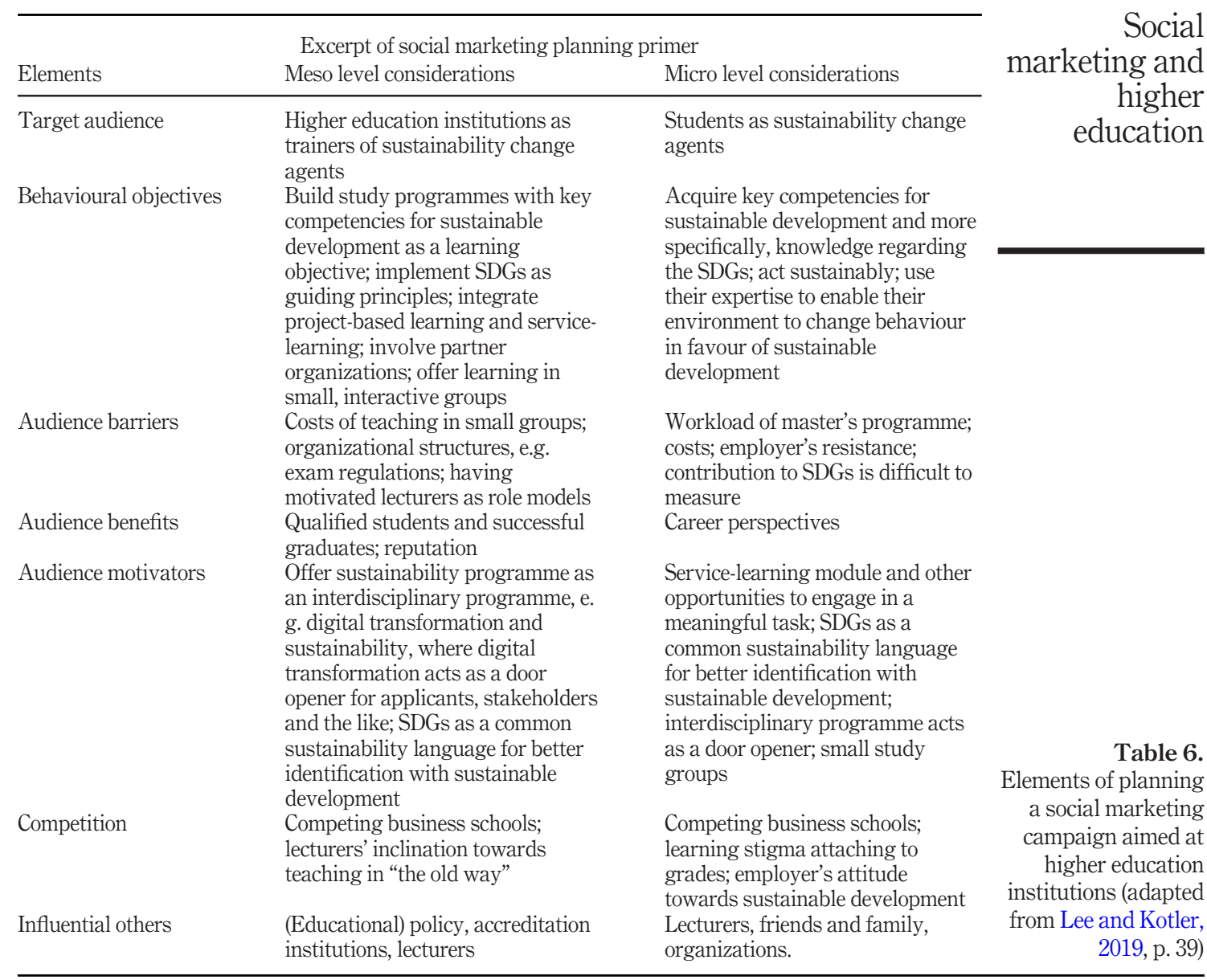

programme, namely, its interdisciplinary and project-based approach and its open, interactive culture under the umbrella of the SDGs, have the potential to equip students with key competencies for sustainable development, thereby educating them as change agents regardless of their discipline and areas of expertise (Figure 2). We conclude that to achieve greater awareness and impact regarding the achievement of the SDGs, as many higher education institutions as possible should engage in educating change agents by means of this guideline, which has the SDGs as an umbrella.

Universities and their students are, hence, identified as promising target groups for the social marketing discipline and the results provide practical implications for social marketers in particular.

\section{Practical implications}

By aligning the theory of two separate disciplines, namely, higher education on sustainability and social marketing, the latter is provided with practical guidance regarding 
the planning of a social marketing campaign to increase the awareness of the SDGs and foster progress towards their achievement. The study advices social marketers in terms of the potential target audience, behavioural objectives, audience barriers, benefits, motivators, competition and influential others on micro and meso level. Moreover, the study demonstrates the real-life impact of students in fostering behavioural change towards sustainable development at the individual, organizational and institutional levels. However, the macro-level impact can only be estimated, especially due to the limited time horizon of the case. Social marketing has the potential to scale this impact of universities at a higher level when it successfully addresses the barriers of the target audience in a carefully designed campaign that builds on the presented benefits and motivators.

We conclude that the social marketing discipline can take these insights on higher education on sustainability into account in creating campaigns that target universities as important partners to educate students as sustainability change agents to increase the awareness of the SDGs and foster impact regarding their achievement.

\section{Limitations and outlook}

Some limitations to this study should be noted. The social marketing planning primer is far from complete (Lee and Kotler, 2019, p. 39). We were only able to cover parts of it and did not include questions on issues such as the budget [...] or the marketing mix in form of the 4 Ps (product, place, price, promotion). One of the explanations is that initially, the investigated programme was not intended to be taken as a social marketing campaign target or pilot study.

Regarding the impact of the study programme, we concede that, although we interviewed students from more than one cohort, we cannot speak of any long-term effects yet, as the programme has only been in existence for three years. In addition, one of the interviewed students mentioned that impact in the form of an exact contribution to the SDGs is hardly measurable. In addition, the study cannot exclusively tie impacts on the SDGs to the influence of the study programme, as many other factors also influence students, e.g. their workplace. In one of the interviews, a lecturer reported the following:

I believe that the chance for a change in action and behaviour is above average [.. .] However, it has to be practised. Studying alone is not enough for that from my point of view.

In the present study, however, duality is seen as an element of a part-time study programme and the integration of work, i.e. organizations as external stakeholders, has been recommended as an objective of the social marketing campaign. Nevertheless, further research is required to ascertain the relationship between higher education and sustainability and the consequent impact. One of the major limitations of the study was the sample size, which was partly offset by multiple sources of evidence. Nevertheless, the findings of this paper cannot be generalized. However, the case allowed for an in-depth exploration of an issue, the results of which can now be taken as a starting point for future research.

To inform social marketing on additional aspects of the planning primer, we believe that social marketers should apply the methods of this study to more cases at other universities and to programmes from other disciplines, as well as undertake a pilot study to investigate its practicality. Such a pilot study could also shed light on individual aspects of the planning primer, e.g. the role of the lecturer as a motivator of students. In addition, when lecturers act as sustainability change agents themselves, this would expand the opportunities for social marketing in adopting the proposed approach. Future research on lecturers' role as motivators and their impact with regard to the SDGs by becoming change agents themselves would therefore, be of interest. Answers to questions such as what motivates 
lecturers to engage as role models for sustainable behaviour (Kanashiro et al., 2020, p. 17) and what impact they generate as change agents for the SDGs could enrich the details of the proposed social marketing planning primer. The effect of grading in a learning environment that largely depends on creative collaboration and is set to foster sustainable behaviour is another area for future research that is closely linked with barriers for the student audience.

\section{Notes}

1. www.engineering.uiowa.edu/college/distinguished-lecture-series/miller-distinguished-lecture

2. www.hsba.de/en/hsba/our-university/profile/

3. www.hsba.de/en/studies/master/digital-transformation-sustainability-msc/

4. www.hsba.de/en/studies/master/digital-transformation-sustainability-msc/

5. www.hsba.de/en/studies/master/digital-transformation-sustainability-msc/

6. www.hsba.de/en/studies/master/digital-transformation-sustainability-msc/

7. www.kth.se/en/studies/master/sustainable-production-development/description-1.846296 (accessed 20 February 2021).

8. www.hpu.edu/cla/history-intstudies/sustainability/index.html\#: :text=HPU $\% 27 \mathrm{~s} \% 20$ Master $\% 20$ of $\%$ 20Arts $\% 20$ in,in $\% 20$ the $\% 20$ world $\% 20$ of $\% 20$ sustainability.\&text=Now $\% 20$ is $\% 20$ the $\% 20$ time $\% 20$ to, around \%20one \%20for \%20future\%20generations! (accessed 20 February 2021).

9. www.leuphana.de/fileadmin/user_upload/professional_school/weiterbildung/ma_sustainable_chemistry/ files/flyer-master-sustainable-chemistry.pdf (accessed 20 February 2021).

10. www.hsba.de/en/studies/master/digital-transformation-sustainability-msc/

\section{References}

Andreasen, A.R. (2002), "Marketing social marketing in the social change marketplace", Journal of Public Policy \& Marketing, Vol. 21, No. 1, pp. 3-13, doi: 10.1509/jppm.21.1.3.17602.

Andreasen, A.R. (2006), Social Marketing in the 21st Century, SAGE Publications, Thousand Oaks, CA.

Annan-Diab, F. and Molinari, C. (2017), "Interdisciplinarity: practical approach to advancing education for sustainability and for the sustainable development goals", The International Journal of Management Education, Vol. 15, No. 2, pp. 73-83, doi: 10.1016/j.ijme.2017.03.006, Part B.

Avelar, A.B.A., da Silva-Oliveira, K.D. and da Silva Pereira, R. (2019), "Education for advancing the implementation of the sustainable development goals: a systematic approach", The International Journal of Management Education, Vol. 17, No. 3, pp. 1-15, doi: 10.1016/j. ijme.2019.100322.

Brennan, L., Previte, J. and Fry, M.L. (2016), "Social marketing's consumer myopia: applying a behavioural ecological model to address wicked problems", Journal of Social Marketing, Vol. 6 No. 3, pp. 219-239, doi: 10.1108/JSOCM-12-2015-0079.

Cameron, E. and Green, M. (2015), Making Sense of Change Management: A Complete Guide to the Models, Tools and Techniques of Organizational Change, Kogan Page, London.

Carvalho, H.C. and Mazzon, J.A. (2015), "A better life is possible: the ultimate purpose of social marketing”, Journal of Social Marketing, Vol. 5 No. 2, pp. 169-186, doi: 10.1108/JSOCM-05-20140029 .

Corriveau, M. (2020), "Developing authentic leadership as a starting point to responsible management: a Canadian university case study", The International Journal of Management Education, Vol. 18, No. 1, pp. 1-10, doi: 10.1016/j.jime.2020.100364. 
Creswell, J.W. (2007), Qualitative Inquiry \& Research Design - Choosing Among Five Approaches, SAGE Publications, Thousand Oaks, CA.

Dann, S. (2010), "Redefining social marketing with contemporary commercial marketing definitions", Journal of Business Research, Vol. 63, No. 2, pp. 147-153, doi: 10.1016/j.jbusres.2009.02.013.

De Paula Arruda Filho, N. and Przybylowicz Beuter, B.S. (2020), "Faculty sensitization and development to enhance responsible management education", The International Journal of Management Education, Vol. 18, No. 1, pp. 1-9, doi: 10.1016/j.ijme.2019.100359.

Duffy, S., Van Esch, P. and Yousef, M. (2020), "Increasing parental leave uptake: a systems social marketing approach", Australasian Marketing Journal, Vol. 28, No. 2, pp. 110-118, doi: 10.1016/j. ausmj.2020.01.007.

Eisenhardt, K.M. and Graebner, M.E. (2007), "Theory building from cases: opportunities and challenges", The Academy of Management Journal, Vol. 50, No. 1, pp. 25-32, doi: 10.2307/ 20159839.

Frank, T. and Cort, T. (2020), "Report of results global survey on sustainability and the SDGs", available at: www.globalsurvey-sdgs.com/wp-content/uploads/2020/01/ 20200205_SC_Global_Survey_Result-Report_english_final.pdf (accessed 17 July 2020)

French, J. and Gordon, R. (2015), Strategic Social Marketing, SAGE Publications, Thousand Oaks, CA.

French, J. and Russell-Bennett, R. (2015), “A hierarchical model of social marketing”, Journal of Social Marketing, Vol. 5, No. 2, pp. 139-159, doi: 10.1108/JSOCM-06-2014-0042.

Geller, E.S. (1989), "Applied behavior analysis and social marketing: an integration for environmental preservation”, Journal of Social Issues, Vol. 45, No. 1, pp. 17-36, doi: 10.1111/j.1540-4560.1989.tb01531.x.

Gentile, M. C. (2017), "Giving voice to values: a global partnership with UNGC PRME to transform management education", The International Journal of Management Education, Vol. 15, No. 2, pp. 121-125, doi: 10.1016/j.ijme.2017.02.004, Part B.

Geringer, T., Wendt, S. and Hensel-Börner, S. (2020), "Corporate social responsibility online: designing high-performance websites simultaneously reducing their CO2-emission impact", in Leal Filho, W., Luetz, J. and Ayal, D. (Eds), Handbook of Climate Change Management, Springer Gabler Verlag, Basel, pp. 1-25, doi: 10.1007/978-3-030-22759-3_160-1.

Goffin, K., Åhlström, P., Bianchi, M. and Richtnér, A. (2019), "State-of-the-art: the quality of case study research in innovation management", Journal of Product Innovation Management, Vol. 36, No. 5, pp. 586-615, doi: 10.1111/jpim.12492.

Haertle, J., Parkes, C., Murray, A. and Hayes, R. (2017), "PRME: building a global movement on responsible management education", The International Journal of Management Education, Vol. 15, No. 2, pp. 66-72, doi: 10.1016/j.ijme.2017.05.002, Part B.

Hernández-López, L.E., Álamo-Vera, F.R., Ballesteros-Rodríguez, J.L. and De Saá-Pérez, P. (2020), "Socialization of business students in ethical issues: the role of individuals' attitude and institutional factors", The International Journal of Management Education, Vol. 18, No. 1, pp. 1-12, doi: $10.1016 /$ j.ijme.2020.100363.

iSMA (2013), "The process of developing the consensus definition", available at: https://web.archive.org/ web/20201124002605/https://www.i-socialmarketing.org/index.php?option=com_content\&view= article\&id=84: social-marketing-definition\&catid=28:front-page\#.YBvj7Zeg9PZ $\quad$ (accessed 4 February 2021)

iSMA (2017), "Global consensus on social marketing principles, concepts and techniques", available at: https://isma.memberclicks.net/assets/Documents_Shared_Website/ESMA, \% 20AASM, $\%$ 20SMANA $\% 20$ iSMA $\% 20$ endorsed $\%$ 20Consensus $\% 20$ Principles $\% 20$ and $\%$ 20Concepts \%20paper.pdf (accessed 18 July 2020)

Kanashiro, P., Rands, G. and Starik, M. (2020), "Walking the sustainability talk: if not us, who? If not now, when?", Journal of Management Education, Vol. 44, No. 6, pp. 822-851, doi: 10.1177/ 1052562920937423. 
Kassirer, J., Lefebvre, C., Morgan, W., Russell-Bennett, R., Gordon, R., French, J., Suggs, L.S., Lee, N. and Biroscak, B.J. (2019), "Social marketing comes of age: a brief history of the community of practice, profession and related associations, with recommendations for future growth", Social Marketing Quarterly, Vol. 25, No. 3, pp. 209-225, doi: 10.1177/1524500419866206.

Kelly, K.J. (2013), “Academic course offerings in social marketing: the beat continues”, Social Marketing Quarterly, Vol. 19, No. 4, pp. 290-295, doi: 10.1177/1524500413507825.

Killian, S., Lannon, J., Murray, L., Avram, G., Giralt, M. and O’Riordan, S. (2019), “Social media for social good: student engagement for the SDGs", The International Journal of Management Education, Vol. 17, No. 3, pp. 1-12, doi: 10.1016/j.jime.2019.100307.

Kohlbacher, F. (2006), "The use of qualitative content analysis in case study research", Forum Qualitative Sozialforschung/Forum: Qualitative Social Research, Vol. 7 No. 1, doi: 10.17169/fqs7.1.75, Art. 21.

Kolb, M., Fröhlich, L. and Schmidpeter, R. (2017), "Implementing sustainability as the new normal: responsible management education - from a private business school's perspective", The International Journal of Management Education, Vol. 15, pp. 280-292, doi: 10.1016/j. ijme.2017.03.009.

Kotler, P. and Zaltman, G. (1971), "Social marketing: an approach to planned social change", Journal of Marketing, Vol. 35, No. 3, pp. 3-12, doi: 10.1177/002224297103500302.

Kotter, J.P. (2018), "8 steps to accelerate change in your organization, eBook", available at: www. kotterinc.com/research-and-perspectives/8-steps-accelerating-change-ebook/ (accessed 24 September 2020).

Kuckartz, U. (2019), “Qualitative content analysis: from kracauer's beginnings to today's challenges”, Forum Qualitative Sozialforschung/Forum: Qualitative Social Research, Vol. 20, No. 3, doi: 10.17169/fqs-20.3.3370, Art. 12.

Lee, N.R. and Kotler, P. (2011), Social Marketing: Influencing Behaviors for Good, 4th ed., SAGE Publications, Thousand Oaks, CA.

Lee, N.R. and Kotler, P. (2019), Social Marketing: Behavior Change for Social Good, 6th ed., SAGE Publications, Thousand Oaks, CA.

Lefebvre, R.C. (2012), “Transformative social marketing: co-creating the social marketing discipline and brand", Journal of Social Marketing, Vol. 2, No. 2, pp. 118-129, doi: 10.1108/20426761211243955.

McKenzie-Mohr, D. (2000), "Promoting sustainable behavior: an introduction to community-based social marketing”, Journal of Social Issues, Vol. 56, No. 3, pp. 543-554, doi: 10.1111/00224537.00183.

Mayring, P. (2010), Qualitative Inhaltsanalyse: Grundlagen und Techniken, 11., aktualisierte und überarbeitete Auflage, Beltz Verlag, Weinheim und Basel.

Merriam, S.B. (2009), Qualitative Research: A Guide to Design and Implementation, Wiley, Hoboken, NJ.

Molderez, I. and Fonseca, E. (2018), "The efficacy of real-world experiences and service learning for fostering competences for sustainable development in higher education", Journal of Cleaner Production, Vol. 172, pp. 4397-4410, doi: 10.1016/j.jclepro.2017.04.062.

Moratis, L. and Melissen, F. (2021), "Bolstering responsible management education through the sustainable development goals: three perspectives”, Management Learning, Online First, doi: 10.1177/1350507621990993, available at: https://journals.sagepub.com/page/help/online-first

Ndubuka, N.N. and Rey-Marmonier, E. (2019), "Capability approach for realising the sustainable development goals through responsible management education: the case of UK business school academics", The International Journal of Management Education, Vol. 17, No. 3, pp. 1-14, doi: 10.1016/j.ijme.2019.100319.

Ortiz, D. and Huber-Heim, K. (2017), "From information to empowerment: teaching sustainable business development by enabling an experiential and participatory problem-solving process in 
the classroom", The International Journal of Management Education, Vol. 15, No. 2, pp. 318-331, doi: 10.1016/j.ijme.2017.03.008, Part B.

Parkinson, J., Russell-Bennett, R. and Previte, J. (2018), "Challenging the planned behavior approach in social marketing: emotion and experience matter", European Journal of Marketing, Vol. 52, Nos 3/4, pp. 837-865, doi: 10.1108/EJM-05-2016-0309.

Prestin, A. and Pearce, K.E. (2010), "We care a lot: formative research for a social marketing campaign to promote school-based recycling", Resources, Conservation and Recycling, Vol. 54, No. 11, pp. 1017-1026, doi: 10.1016/j.resconrec.2010.02.009.

Ramboarisata, L. and Gendron, C. (2019), "Beyond moral righteousness: the challenges of nonutilitarian ethics, CSR and sustainability education", The International Journal of Management Education, Vol. 17, No. 3, pp. 1-12, doi: 10.1016/j.ijme.2019.100321.

Rynes, S. and Gephart, R.P. Jr. (2004), "From the editors: qualitative research and the 'academy of management journal"', The Academy of Management Journal, Vol. 47, No. 4, pp. 454-462, availale at: www. jstor.org/stable/20159596

Saunders, S.G., Barrington, D.J. and Sridharan, S. (2015), "Redefining social marketing: beyond behavioural change", Journal of Social Marketing, Vol. 5, No. 2, pp. 160-168, doi: 10.1108/JSOCM03-2014-0021.

Schreier, M. (2012), Qualitative Content Analysis in Practice, SAGE, Thousand Oaks, CA.

Sen, A. (1999), Development as Freedom, Oxford University Press, Oxford.

Siggelkow, N. (2007), "Persuasion with case studies", The Academy of Management Journal, Vol. 50, No. 1, pp. 20-24, doi: 10.2307/20159838.

Stephens, J.C., Hernandez, M.E., Román, M., Graham, A.C. and Scholz, R.W. (2008), "Higher education as a change agent for sustainability in different cultures and contexts", International Journal of Sustainability in Higher Education, Vol. 9, No. 3, pp. 317-338, doi: 10.1108/14676370810885916.

Storey, M., Killian, S. and O'Regan, P. (2017), "Responsible management education: mapping the field in the context of the SDGs", The International Journal of Management Education, Vol. 15, No. 2, pp. 93-103, doi: 10.1016/j.jime.2017.02.009, Part B.

Truong, V.D. (2014), "Social marketing: a systematic review of research 1998-2012", Social Marketing Quarterly, Vol. 20, No. 1, pp. 15-34, doi: 10.1177/1524500413517666.

Truong, V.D. and Dietrich, T. (2018), "Master's thesis research in social marketing (1971-2015)”, Journal of Social Marketing, Vol. 8 No. 1, pp. 58-98, doi: 10.1108/JSOCM-11-2016-0072.

Truong, V.D., Saunders, S.G. and Dong, X.D. (2019), "Systems social marketing: a critical appraisal", Journal of Social Marketing, Vol. 9 No. 2, pp. 180-203, doi: 10.1108/JSOCM-06-2018-0062.

United Nations (2015), “Transforming our world: the 2030 agenda for sustainable development", available at: www.un.org/en/development/desa/population/migration/generalassembly/docs/ globalcompact/A_RES_70_1_E.pdf (accessed 23 July 2020)

Van Esch, P. (2017), Social Marketing - A Rough Guide, Marketing Science Press, Philadelphia.

Van Esch, P. and Van Esch, L. (2013), "Justification of a qualitative methodology to investigate the emerging concept: the dimensions of religion as underpinning constructs for mass media social marketing campaigns", Journal of Business Theory and Practice, Vol. 1, No. 2, pp. 214-243, doi: 10.22158/jbtp.v1n2p214.

Van Esch, P., Van Esch, L.J. and Cowley, J.C.P. (2013), "The dimensions of religion as underpinning constructs for mass media social marketing campaigns: an emerging concept", International Journal of Marketing Studies, Vol. 5, No. 1, pp. 96-106, doi: 10.5539/ijms.v5n1p96.

Weybrecht, G. (2017), "From challenge to opportunity - management education's crucial role in sustainability and the sustainable development goals - an overview and framework", The International Journal of Management Education, Vol. 15, No. 2, pp. 84-92, doi: 10.1016/j. ijme.2017.02.008, Part B. 
Wiek, A., Withycombe, L. and Redman, C.L. (2011), "Key competencies in sustainability: a reference framework for academic program development”, Sustainability Science, Vol. 6, pp. 203-218, doi: 10.1007/s11625-011-0132-6.

Wood, T. Jr. and Pansarella, L. (2019), "Inside the borders but outside the box: an immersion program aligned with the PRME and the SDG to foster reflexivity", The International Journal of Management Education, Vol.17, No. 3, pp. 1-9, doi: 10.1016/j.ijme.2019.100306.

Yin, R.K. (2009), Case Study Research: Design and Methods, 4th ed., SAGE Publications, Thousand Oaks, CA.

\section{Corresponding author}

Chiara Hübscher can be contacted at: chiara.huebscher@hsba.de

For instructions on how to order reprints of this article, please visit our website: 